\title{
Ethical dilemmas of software engineers
}

\author{
Admirim Aliti \\ E-Technologies, South East European University, ad-mirim@gmail.com
}

\begin{abstract}
The aim of this paper is to analyze the ethical dilemmas that IT professionals in general, and software engineers in particular, face in the Balkans, specifically in Macedonia, Kosovo and Albania. In an environment where there is still an absence of policies regarding ethics and best practices, developers' perceptions and their dilemmas are investigated. The paper first gives a general overview of the social and cultural issues in these countries, and then follows an analysis of issues regarding software development, good and bad work practices, and developers' reactions to these issues. In this research, varying security and privacy compliance situations are explored through qualitative interviews of 6 developers that work in domestic and foreign developing companies in Macedonia, Kosovo and Albania: how they deal with dilemmas, how they make decisions and how they ensure that users are never harmed - was the objective of this investigation. Some conclusions are drawn based on participants' reported perceptions regarding these issues.
\end{abstract}

Keywords: ethics, ethical dilemmas, software developers, Macedonia, Kosovo, Albania, Corruption, IT companies

\footnotetext{
(C) 2015 Admirim Aliti. This is an Open Access article distributed under the terms of the Creative Commons Attribution-NonCommercial 4.0 International License (http://creativecommons.org/licenses/by-nc/4.0/), permitting all non-commercial use, distribution, and reproduction in any medium, provided the original work is properly cited.

http://dx.doi.org/10.15626/dirc.2015.07
} 


\section{Introduction}

Information Technology companies are one of the most important entities of our time and they are central to the operations of industrial societies. Without them, much of the manufacturing industry, commerce, transport and distribution, government, the military, health services, education, and research would simply grid to a halt (Forester and Morrison, 1993). Accidents with computer-related devices and the misuse of them have created social problems such as computer crime, software theft, hacking, the creation of viruses, invasion of privacy and workplace stress (Stamatelloss, 2007).

Each of these problems creates ethical dilemmas for computer professionals and users. Ethical theory and professional codes of ethics can help resolve these ethical dilemmas to some extent, while computing education has a special responsibility to try to ensure more ethical behavior among future computer developers (Forester and Morrison, 1993).

As with other concepts, ethics is closely affected by other factors, i.e., academia and work culture of the specific place in the world where IT companies operate. In this research, I have conducted interviews with programmers/developers who work in software development companies in Macedonia, Kosovo and Albania. I have discussed issues of ethics and moral dilemmas in the process of their work. All participants in this research are perceived as part of one group, as there were many similarities between participants' perception about ethics.

Following this introduction, there is a section which explains the motivation for this research. Additionally, I have a section on ethical dilemmas linked to IT professionals and companies dealing with software and information. Afterwards I briefly explain the method, how this investigation was conducted, by outlining the profiles of participants and their places of work.

That is followed by a section on analysis and findings - which maps empirical data with research themes. Then I have a section of recommendations, which are main recommendations linked to the findings of the research. I conclude the paper with conclusions of the research and of this paper.

\section{Motivation}

The motivation to do this kind of research stems from several reasons, some of which I will discuss here.

First, ethics should be one of the main concerns of today's IT organizations. I wanted to explore how ethics is perceived by IT personnel in companies in Macedonia, Kosovo and Albania. Since these countries are in close proximity to each other, many of these companies share similar values and work ethics.

Secondly, since these countries are part of the developing world, where there is still high levels of corruption, it is important to see how employees face these issues; when do they have moral dilemmas - and how do they solve them. 
After the interviews, and based on the answers of interviewees, I will give some recommendations on how to improve the level of ethics in IT based companies.

\section{Ethical Dilemmas}

New computer technologies for gathering, storing, manipulating, and communicating data are revolutionizing the use, availability and accessibility of information. Along the way, they are also creating ethical dilemmas. The speed and efficiency of electronic information systems, which include local and global networks, databases, and programs for processing information, force people to confront entirely new rights and responsibilities in their use of information and to reconsider standards of conduct.

An ethical dilemma involves a decision making opportunity in which there seems like there is no right choice to make. They tend to involve behavioral choices where the resolution or decision affects others as well as the self (Alavudeen, Rahman, and Jayakumaran, 2008).

Ethics include moral choices made by individuals in relation to the rest of the community, standards of acceptable behaviour, and rules governing members of a profession. The broad issues relating to electronic information systems include control of and access to information, privacy and misuse of data, and international considerations, because different regions and countries have different perceptions about these concepts.

\section{Method for this research}

\section{Worldview}

This research work adopts a social constructivist worldview, because I believe that objects are human-made entities that cannot be separated from their social context and human influences. In the given case, I explore how social phenomena or objects of consciousness develop in social contexts.

Within this view, social construction is the practice that is constructed by programmers, as reported by them in their interviews. Since reality is socially constructed, I focus on its dependence on factors of the social selves rather than any inherent quality that it possesses in itself. In order to understand and explore these objects, they are studied in the real-life contexts where they exist (Lee, 2004). This research tries to explore and understand employees' perceptions of computer ethics and how they deal with their work-related moral dilemmas.

Research type and participants

This research employs a case study approach which helps us to identify and contextualize the human factors involved in information systems (Yin, 2003). First, data collection and data analyses have been completed, with the aim of obtaining 
improved understanding of IT employees' perceptions regarding ethics and moral dilemmas. According to Cresswell (2013), a case study approach allows an indepth exploration of a program, activity or process, in our case of Information Systems ethics and the human factors related to improving it.

Participants in the interviews are 6 IT engineers who work in IT companies in Macedonia, Kosovo, and Albania. I have interviewed 2 participants from each country about their different views and perspectives. This choice of participants enables collection of different views about IS ethics from those who are tasked to develop and complete products for clients. The interviews were unstructured in order to derive important themes from the developers themselves.

I have ensured that all participants have the right to voluntarily participate in interviews and observations, and at the beginning of each interview I have explained to them that they have the right to leave the interview or skip any question posed to them. Additionally, I have made sure that their companies do not forbid them to participate in academic research. Several strategies to validate the findings have been used, like inter rater reliability, with the final purpose of creating reader confidence in the accuracy of the research findings (Cresswell, 2013).

\section{Analysis and Findings}

In this section, the gathered data from interviews are analyzed by mapping the empirical data to the research themes, which emerged from analysis. Findings are briefly explained.

Lack of Ethics course

All interviewees confirmed that they have never taken Ethics course in University or in their companies. This is important to note, considering the fact that all of them have at least Bachelor degree in Computer Science or related fields, and two of them are PHD candidates.

Importance of ethics in informatics

Most interviewees claim that ethics (except for work ethic, or behavior with their colleagues) is not very important in their job, because they perceive their job as being technical. Usually, developers do not have any communication with clients. They only get specifications from project managers when they work on the product.

Relationship with clients

By default, there is no communication between IT engineers who work on certain products and the client who is going to use the product.

One of the interviewees who currently works as a developer, but who has worked previously as a project manager, recommends more communication between de- 
velopers and clients, so developers can better "sense their clients' concerns and their real world situation".

Moral dilemmas - "management decides"

When asked for cases when the company is not fair with the client (i.e., product is beyond deadline, or not completed), most developers claim that they have no moral dilemmas as long as this decision has been made by the management. So in cases when the product has not been properly completed - and when developers have asked for more time or more tools - and when management "hides" the problem, developers put the blame on their boss, thus having no moral and psychological discomfort.

Putting software live without testing - "normal"

In most interviews, cases of not testing the software and putting the software live without "peer review" were reported. Participants claim that this happens often, and that they have no moral discomfort about this because, as they say, in this market, this is "normal" procedure.

This was emphasized especially by one participant, who at the same time works for one local company and one American company (virtually). He says that issues of not testing features, delays in software completion, etc. happen in the former, but not in the latter due to good planning by the company. So according to this developer, this is related to the culture of the country where the company operates.

Corruption in tendering - make companies less competitive

Some interview participants say that they are aware of cases when the price for the product is increased many fold because the company has to illegally pay bribes to the people in the public institution who granted them the project.

This information, however, is usually only known by a small number of people in the company, including the boss. This level of corruption makes the company less competitive, which especially affects other companies who want to buy or implement similar products. Participants claim that these companies have better leverage and prize when purchasing the same software from outside the country, for example, Western Europe, than buying the same product with this, so called, "artificial price".

\section{Recommendations}

In this section I will point out some recommendations based on the findings of the research. 
Need for Ethics course education

While software development companies cannot determine the curriculum in academia, which currently lacks Ethics course, they can organize sessions or lectures regarding Ethics. These lectures/presentations would be very beneficial to the IT personnel, who would become aware of main concepts regarding Ethics in the Information Systems field. Findings from this research suggest that most participants are not aware of accidents in IT - such as Therac 25 or Ariane. Having knowledge of this kind of accidents would make IT engineers more conscious of the repercussions of bad practices and/or erroneous decisions taken by the management of a company.

So companies should bring Ethics subject related knowledge to their employees, since this is something which these engineers did not receive in their academic education.

More "communication" between programmer/developer and client

More communication is necessary between the programmer/developer of the software and the client who will be using it. The intention of this recommendation is that developers need to be aware of the main concerns of the client who has ordered the product. This communication does not have to be direct; it can be organized indirectly. Project managers and other people in the company, who negotiate specifications with the client, can act as a link and bring clients' perceptions to the developers.

Being more rigorous in implementing standards and best practices Management should develop, or adapt to, standards when developing software products. In the context of this research, this means that every software product is developed on time, and tested properly before it goes live In the context of this research - it is necessary that every software product is developed in time, and tested properly before it goes live.

When ethics concepts are properly absorbed by employees and when product standards are in place, developers can easily become more effective and could navigate any moral dilemmas when doing their job.

\section{Conclusions}

Ethical dilemmas exist in IT companies, similar to other organizations. This research focused on ethical dilemmas that programmers/developers have in the process of developing products for their clients. Findings reveal that the context for and perceptions about Ethical dilemmas are shaped by local culture and influenced by national practices.

This study suggests that engineers in IT companies in Macedonia, Kosovo and Albania have received no Ethics education, neither a course undertaken in Academia or presentations delivered in the company. One way forward would be 
to introduce some ethics sessions in Balkan IT companies, which would be immediately beneficial to employees and also, in long term, to the companies which employ such practices.

\section{References}

Alavudeen, A., Rahman, R.K, and Jayakumaran, M., 2008. Professional Ethics and Human Values. New Delhi: Laxmi Publications.

Cresswell, J. W., 2013. Research design: qualitative, quantitative, and mixed methods approach. 4th ed. Los Angeles: Sage Publications, Inc.

Forester, T. and Morrison, P., 1993. Computer ethics: cautionary tales and ethical dilemmas in computing. Cambridge, MA: The MIT Press.

Lee, A., 2004. Thinking about Social Theory and Philosophy for Information Systems. In: J. Mingers and L. Willcocks (eds.), Social Theory and Philosophy for Information Systems. Chichester: Wiley, pp. 1-26.

Stamatelloss, G., 2007. Computer Ethics: A Global Perspective. Sudbury, MA: Jones and Bartlett Publishers.

Yin, R. K., 2003. Applications of Case Study Research 2nd Ed. Thousand Oaks, CA: Sage Publications. 